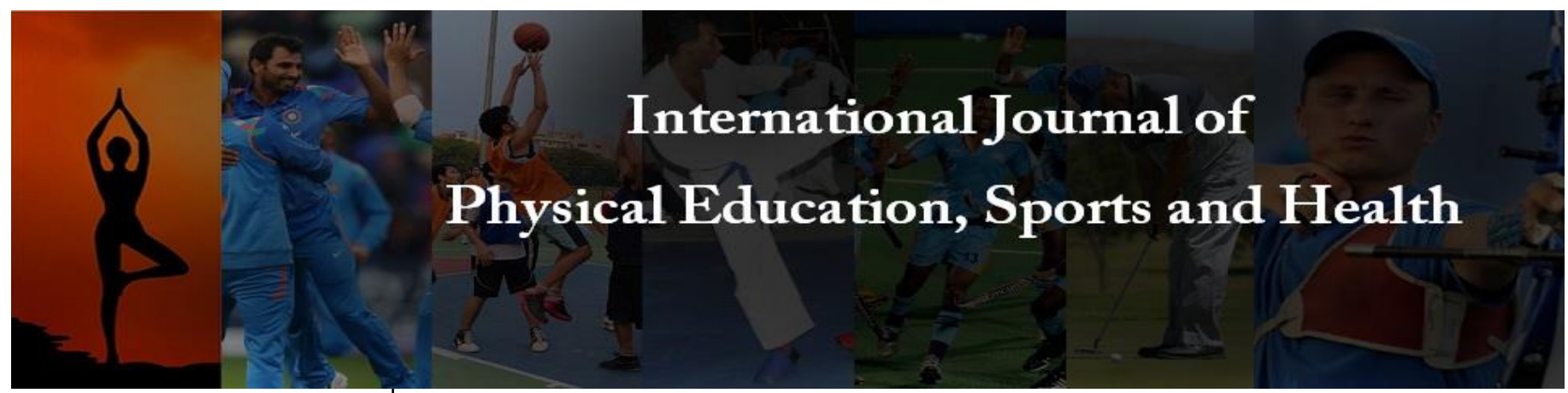

P-ISSN: 2394-1685

E-ISSN: 2394-1693

Impact Factor (ISRA): 5.38

IJPESH 2022; 9(1): 32-34

(C) 2022 IJPESH

www.kheljournal.com

Received: 19-11-2021

Accepted: 21-12-2021

\section{Asit Mahara}

Research Scholar,

Department of Physical

Education and Sport Science,

Vinaya bhavana, Visva-Bharati,

Santiniketan, West Bengal,

India

\section{Dr. Sentu Mitra}

Assistant Professor,

Department of Physical

Education and Sport Science,

Vinaya bhavana, Visva-Bharati,

Santiniketan, West Bengal,

India

Sagarika Bandyopadhyay

Professor, Department of

Physical Education and Sport

Science, Vinaya bhavana, Visva-

Bharati, Santiniketan, West

Bengal, India
Corresponding Author: Asit Mahara

Research Scholar,

Department of Physical

Education and Sport Science,

Vinaya bhavana, Visva-Bharati,

Santiniketan, West Bengal,

India

\section{Effect of asanas on dynamic balance of sedentary women}

\author{
Asit Mahara, Dr. Sentu Mitra and Sagarika Bandyopadhyay
}

DOI: https://doi.org/10.22271/kheljournal.2022.v9.i1a.2336

\section{Abstract}

The objective of the study was to find out the "Effect of asanas on dynamic balance of sedentary women". For the purpose of the study sixty sedentary women were selected purposively from Bolpur, Birbhum, West Bengal, India as the subject. They were categorized into two age group of 30 to 40 years $(\mathrm{n}-30)$ and 41 to 50 years (n-30). Each age group were also divided into two- experimental group (n-15) and control group (n-15). Dynamic balance was selected as the variable for the study. Eight weeks training of the selected asanas were given to both the experimental groups. Pre-test and post-test data of all the groups were taken by using modified bass test. To calculate the data descriptive statistics, Analysis of Co-variance (ANCOVA) and LSD post-hoc test were used. The level of significance was set at 0.05 level. The result revealed the significant effect on dynamic balance of the age of 30-40 years group (F13.114) but not significant for 41-50 years group (F-3.752). On the basis of the result, it was concluded that asanas have significant effect on dynamic balance of younger aged sedentary women group.

Keywords: yogic practice, asana, fitness, dynamic balance, sedentary women

\section{Introduction}

Indian history is closely related to the awareness of health and physical activity where male engage first then female slowly engage. Normally female candidates participated less in physical activity. However, in rural area female candidates are engaged in physical activity but not in urban area. Normally house wife did not participate in regular activity, or lack of time involved in regular physical activity, because our society is till not allowing them to do so and also there is various responsibilities in daily life such as preparation of children for going school, maintenance of daily works in the house etc. These life-style routine is maintained by the house wife in the daily life, and this is the main cause of decrease in physical fitness of house wife. This less active or not active life-style routine continues for a long gradually lead the house wife in sedentary life which decrease the optimum capacity of internal system of the house-wife. In a different way, this life-style slowly decreases the immunity power of the house wife that ultimately increases chances of various diseases.

Yoga involves a systematic method by which the awareness of the processes of stress relief can be expended and thus gain control over them. Yogic practices enhance quality of life by improving physical, physiological and psycho-social perspectives of human being these are the widely addressed benefits of yoga.

Balance is one of the important fitness components which not only play a vital role for the sports person but also for sedentary people. Balance is of two types- static balance and dynamic balance. Static balance is the ability to maintain the neuromuscular system in a static condition for an efficient response or to control it in a specific efficient position while dynamic balance is the ability to maintain the neuromuscular system in motion. Both the types of balance are equally important according to the nature of activity. Dynamic balance play more important role for the sedentary people then static balance. As the women has less opportunity to do regular physical activity in various places specially in open places, they need some special physical activity like yogic practices which is one of the very easy mode of keeping fitness for all including the sedentary women and can be performed in closed room also. 
There is a few research on dynamic balance specially for the sedentary women. With this background and hard availability of any work on response of women of different age groups on selected parameters after yogic practices, this study was undertaken. The objective of the study was to find out the effect of asanas on dynamic balance of sedentary women.

\section{Methodology}

Subjects: For the purpose of the study sixty sedentary women were selected purposively from Bolpur, Birbhum, West Bengal, India as the subject. They were categorized into two age group of 30 to 40 years (n-30) and 41 to 50 years (n-30). Each age group were also divided into two- experimental group (n-15) and control group (n-15).

Variable: Dynamic balance was selected as the variable for the study.

Test and Criterion Measure: To measure the dynamic balance of different age group sedentary women, modified bass test of dynamic balance was used. The score of the subject on modified bass test of dynamic balance was recorded in number.

Collection of Data: Pre-test data were collected from both the two experimental groups and two control groups of different age group of sedentary women. Yogic training schedule comprised of vrikshasana, paschimatanasana, yogamudra, sarvangasana, halasana, matsyasana, bhujangasana, salabhasana, dhanurasana, chakkarasana, bakrasanaa, utkatasana and shavasana was administered for six days a week for eight weeks to two experimental groups of 30-40 years age and 41 to 50 years age. The load was gradually increased from $1^{\text {st }}-2^{\text {nd }}$ week to $7^{\text {th }}-8^{\text {th }}$ week. Immediately after completion of the yogic treatment to the experimental group, the post-test data were collected from all the four groups.

Statistical Analysis: To find out the effect of asanas on dynamic balance of sedentary omen, descriptive statistics, Analysis of covariance (ANCOVA) and LSD post-hoc test were applied. The level of significance was set at 0.05 level.

\section{Result and Discussion}

Table 1: Descriptive Statistics of two different Age Group of Sedentary Women

\begin{tabular}{|c|c|c|c|c|c|c|c|c|}
\hline & \multicolumn{3}{|c|}{ 30-40 Years Age Group } & \multicolumn{4}{c|}{ 41-50 Years Age Group } \\
\hline & Experimental Group & \multicolumn{2}{|c|}{ Control Group } & Experimental Group & \multicolumn{3}{c|}{ Control Group } \\
\hline & Pre-Test & Post-Test & Pre-Test & Post-Test & Pre-Test & Post-Test & Pre-Test & Post-Test \\
\hline Mean (sec) & 15.33 & 20.67 & 15.2 & 18.53 & 13.87 & 19.93 & 13.87 & 18.07 \\
\hline Standard Deviation & 3.921 & 4.654 & 4.678 & 5.166 & 4.926 & 6.041 & 3.814 & 4.636 \\
\hline Standard Error & 1.012 & 1.201 & 1.208 & 1.334 & 1.272 & 1.559 & 0.984 & 1.197 \\
\hline Skewness & -0.427 & 0.307 & 0.293 & 0.223 & -0.308 & 0.176 & -0.371 & -0.723 \\
\hline Kurtosis & -0.147 & -0.630 & 0.157 & 1.235 & -1.116 & -0.674 & 0.172 & 0.825 \\
\hline Minimum score & 7 & 14 & 7 & 8 & 5 & 10 & 7 & 8 \\
\hline Maximum score & 20 & 30 & 25 & 30 & 20 & 30 & 20 & 25 \\
\hline Subject Number & 15 & 15 & 15 & 15 & 15 & 15 & 15 & 15 \\
\hline
\end{tabular}

Table 1 describes the mean, standard deviation, Standard error, Skewness, Kurtosis, Maximum score and Minimum score of subjects in dynamic balance of both the groups of sedentary women.

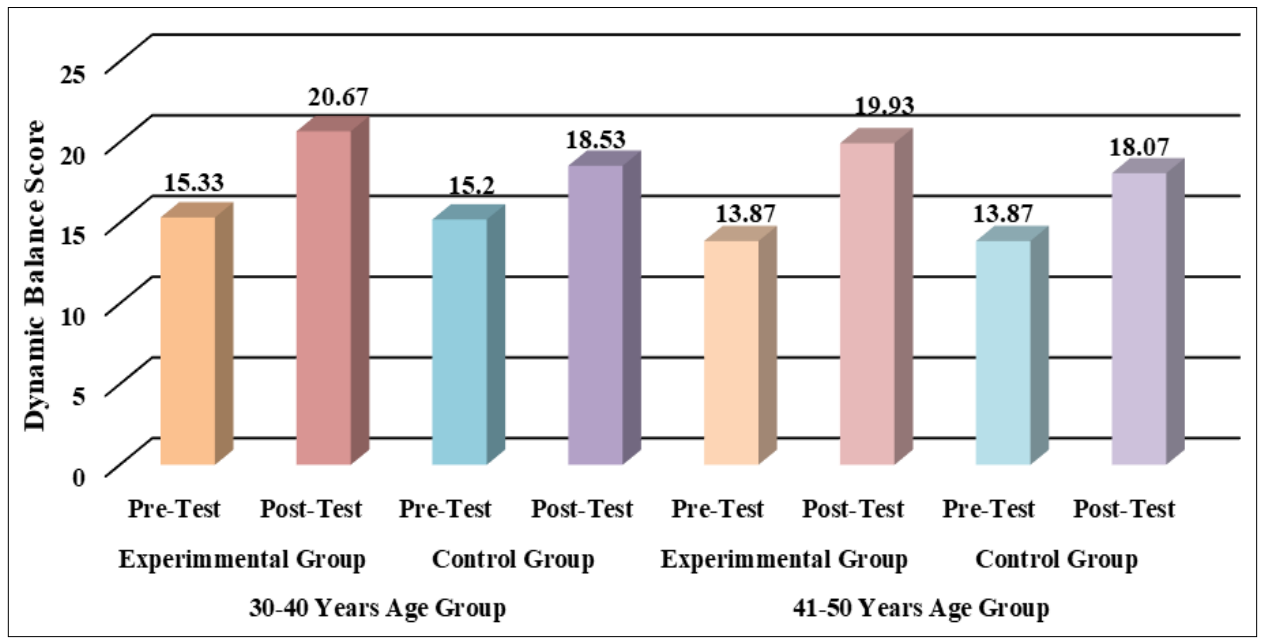

Fig 1: Graphical Representation of Pre-Test \& Post-Test Mean for Distinct Groups on Dynamic Balance of both the Sedentary Women Groups

Table 2: ANCOVA on Dynamic Balance of 30-40 Years Age Group for Pre-Test and Post-Test Data

\begin{tabular}{|c|c|c|c|c|}
\hline Source & df & Sum of Squares & Mean Square & F-value \\
\hline Treatment Group & 1 & 30.005 & 30.005 & \multirow{2}{*}{$5.106^{*}$} \\
\hline Error & 27 & 158.661 & 5.876 & \\
\hline Total & 28 & 188.666 & & \\
\hline
\end{tabular}

Table-2 reveals significant improvement in dynamic balance $(\mathrm{F}=5.106)$ among groups. The obtained $\mathrm{F}$ value was found to greater than that of tabulated $\mathrm{F}$ value 4.22 at 0.05 level of significance with 1, 27 degree of freedom. 
Table 3: Pair wise Comparison of 30-40 Years Age Groups of Adjusted Means on Dynamic Balance obtained in Pre-Test and Post-Test Data

\begin{tabular}{|c|c|c|c|c|c|c|}
\hline Group & N & Pre-Test & Post-Test & Adjusted Mean & Mean Difference & Critical Difference \\
\hline Experimental Group & 15 & 15.33 & 20.67 & 20.60 & \multirow{2}{*}{$2.00^{*}$} & \multirow{2}{*}{1.507} \\
\hline Control Group & 15 & 15.20 & 18.53 & 18.60 & \\
\hline
\end{tabular}

Table-3 in respect to the paired adjusted final mean differences in dynamic balance clearly indicates the significant difference between the experimental and control group $(2.00 *)$ which were greater than that of the critical value 1.644 .

Table 4: ANCOVA on Dynamic Balance of 41-50 Years Age Group for Pre-Test and Post-Test Data

\begin{tabular}{|c|c|c|c|c|}
\hline Source & df & Sum of Squares & Mean Square & \multirow{2}{*}{ F-value } \\
\hline Treatment Group & 1 & 26.133 & 26.133 & \multirow{2}{*}{2.639} \\
\hline Error & 27 & 267.333 & 9.901 & \\
\hline Total & 28 & 293.466 & \\
\hline Table value of $\mathrm{F}(1,27)=4.22 *$. Significant at the .05 level & \\
\hline
\end{tabular}

Table-4 reveals no significant improvement in dynamic balance $(\mathrm{F}=2.639)$ among the groups. The obtained $\mathrm{F}$ value was found lesser than that of the tabulated $F$ value 4.22 at 0.05 level of significance with 1, 27 degree of freedom.

The result revealed that the experimental group of 30-40 years sedentary women significantly improve the dynamic balance $\left(\mathrm{F}=5.106^{*}\right)$ in comparison to the control group whereas the age group of 41-50 years sedentary women did not show significant improvement $(\mathrm{F}=2.639)$ in comparison to the control group. The result might be due to the application of eight weeks Yogasana training and also the age and fitness level of the younger group help them to achieve the significant result. The study was partially supported by the study of Arjun PV and Sunitha KB (2019) ${ }^{[1]}$ who worked on Effect of Yoga Training on Coordinative abilities of High School Students. The variables selected for the study were Eye Hand Coordination, Static Balance, Dynamic Balance and Reaction Time. The subjects of this study were 40 boys, aged between 13-15 years, from GHSS Morazha, Kannur district. They found that in experimental group, significant changes were seen in Eye Hand Coordination, Static Balance, Dynamic Balance and Reaction Time.

\section{Conclusion}

On the basis of the result, it may be concluded that the Yogasana training improve the dynamic balance of the young sedentary women.

\section{References}

1. Arjun PV, Sunitha KB. Effect of Yoga Training on Coordinative abilities of High School Students. International Journal of Yogic, Huan Movement and Sports Sciences. 2019;4(2):63-65.

2. Black K. Applied Business Statistics: Making Better Business Decisions (7 ${ }^{\text {th }}$ ed.) Wiley India Pvt. Ltd. 2014.

3. Johnson Barry L, Nelson Jackson K. Practical Measurements for Evaluation in Physical Education (4th ed.) Macmillan Publishing Company. New York, 1986, 242-243.

4. Saraswati SS. Asana Pranayama Mudra Bandha (Golden Jubilee ed.) Yoga Publication Trust, Munger, Bihar, India, 2013.

5. Singh H. Science of Sports Training. New Delhi: D.V.S. Publications, 1993.

6. Verma JP. A Text Book on Sports Statics. Gwalior, India: Venus Publication, 2000. 